\title{
ECONOMETRIC MODEL FOR PLANNING THE INDUSTRIAL PRODUCTION
}

\author{
Ioan Constantin Dima ${ }^{1}$, Janusz Grabara ${ }^{2}$, Michal Kolcun $^{3}$ \\ ${ }^{1}$ University "Valahia of Targoviste", Romania \\ ${ }^{2}$ Czestochowa University of Technology, Poland \\ ${ }^{3}$ Technical University of Kosice, Slovakia
}

\begin{abstract}
In industrial practice, there are frequent cases when a performer randomly serves the machines at time intervals, which prevents the elements of carrying out the processing procedure from being predetermined. Situations of random interventions on the multiserved machines occur more often in textile industry on the spinning machines, looms, knitting machines, wire weaving and interlacing machines, etc.
\end{abstract}

Keywords: the discipline of waiting, the average number of machines, average waiting time of the machines in the system, the average number of the machines in the system, Poisson law, the test $X^{2}$

\section{Introduction}

In order to mathematically shape the multi-serving of several machines by one performer at random time intervals, it is required to know the main elements featuring that process:

- advents (arrivals) represent the requests for serving the machines by a performer; it is stated by the average number of machines requiring serving in the time unit $(\lambda)$

The process of serving several machines by a performer - in this case - is of random feature, the number of requests being different from intervals to intervals. The average number of requests $(\lambda)$ for the time unit is chosen from the relation:

$$
\begin{gathered}
\lambda=\frac{\sum n_{i} \times f_{\left(n_{i}\right)}}{\sum f_{\left(n_{i}\right)}} \text { or } \lambda=\frac{\sum n_{i} \times f_{\left(n_{i}\right)}}{N} \\
\sum f_{\left(n_{j}\right)}=N
\end{gathered}
$$

where: $n_{i}$ - any category of requests; $f\left(n_{j}\right)$ - frequency of requests in a category (the number of cases in that category $\left.-n_{i}\right) ; \sum f_{\left(n_{j}\right)}$ - the sum of all frequencies 
of requests representing the number $(N)$ of time intervals when the occurrence of requests was noticed, $n_{i} \times f\left(n_{j}\right)$ - the number of units required for a category.

- the service represents the action by means of which one or several performers: resolve the servings and is stated by the average number of services provided on the set time unit; it is noted with $(\mu)$;

- service factor $(\rho)$ is determined from the ratio between the number of units served $(\lambda)$ and the average number of services $(\mu)$.

$$
\rho=\frac{\lambda}{\mu}
$$

If $\rho>1$, it means that the performer is overloaded, and the number of machines waiting shall continuously increase. If $\rho<1$, the performer's serving capacity is good, but due to the random frequency of requirements for serving the machines in the system, they shall have a certain waiting time until they are served;

- the discipline of waiting defined the order in which serving the machines is met, and namely: on a "first come - first served" basis.

For studying the multi-serving conditions, it is necessary to also state the following indicators: the average degree of performer's disengagement $\bar{T}_{e}^{a}$; the average number of machines $\bar{N}_{f}$ from the waiting time of serving within the time interval taken into account; the average waiting time of the machines in the system $\left(\bar{T}_{f}\right)$ is the average time when a machine is waiting to be served; the average number of the machines in the system $\bar{N}_{s}$ shows the average number of machines that are within the time interval stated in the waiting string and at the performer, to be served.

When organising the activity of serving several machines by a performer, it is pursued to simultaneously meet two requirements; the waiting times of the machines to be minimum and performer's occupational average degree to be as high as possible. In order to meet these requirements, it is required the function $f_{(m i)}$ of the costs due to the time wasted, halts and performer's waiting to be minimised, that is:

$$
f_{(m i)}=\bar{W}_{h} \times \bar{T}_{e}^{a}+\bar{P}_{h} \times \bar{N}_{f} \times \bar{T}_{f}
$$

where:

$\bar{W}_{h}$ - represents the productivity of the hourly average work of the worker serving the machine;

$\bar{P}_{h}$ - the value of the average production per hour achieved on the machine unit served. 
The function of optimisation $f_{(m i)}$ is a summation of some losses, stated as value in lei per hour.

For the servings to be performed based on the Poisson law, it is required to meet the condition:

$$
\chi^{2}>\chi_{0}^{2}
$$

where:

$\chi^{2}$ - represents the mathematical expression of the relationships existing between the frequency of the categories of requests and probabilities of their occurrence depending on a certain number of freedom degrees and a certain requirement $\varepsilon$ so the studied phenomenon would approach a theoretic Poisson-type phenomenon, the theoretical values for the function $\chi^{2}$ have been calculated by Pearson and are represented in attachment III.

$\chi_{0}^{2}$ - the practical value of the function calculated based on the data of the phenomenon studied is calculated by means of the relation:

$$
\chi_{0}^{2}=\frac{\sum\left[f_{(n)}-N \times P_{(n)}\right]^{2}}{N \times P_{(n)}}
$$

where: $P_{(n)}$ - represents the theoretical Poisson probability determined for $\varepsilon$ from the practical data and for $n_{i}$ serving categories.

\section{Analysis of models used}

Solving the problem for the organisation of multi-serving several machines by a performer at random time intervals is possible by means of patterns known in literature as closed patterns. It is accepted that a performer serves $N$ homogeneous machines of same type and size, which operate independently. Until a certain moment, these machines operate without supervision or need for the worker's intervention, but at that moment, it is needed for the performer to intervene. If a performer intervenes for commissioning a stopped machine from the group of the machines served, the duration of an intervention being a random variable, then a negative exponential distribution follows, according to the parameter.

Schematically, the system of serving the machines by a performer in time is shown in Figure 1, with the following operating mode.

The sequence of the machines stopping is also the sequence of commissioning by the performer; it results when the discipline of the system is met: "first come first served". 


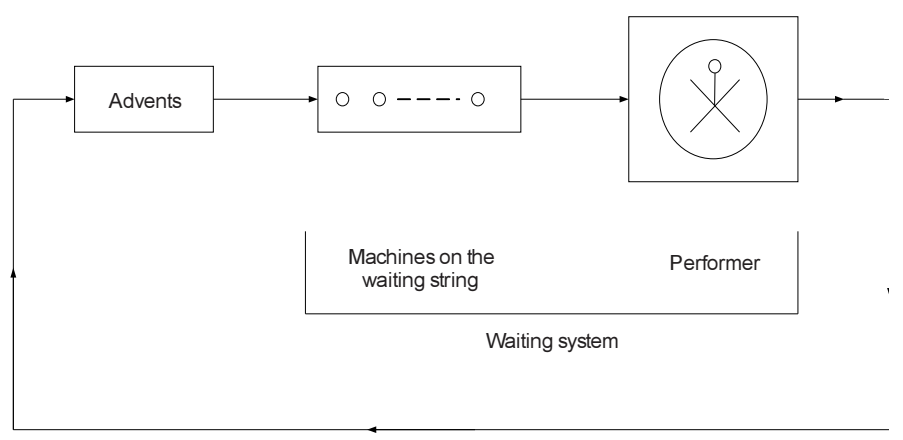

Fig.1. The diagram of the serving system

In order to establish the equations featuring the state of the system, the probability $P n(i+\delta)$ must be stated, so that for the moment $i+\delta$ there would be $\mathrm{n}$ machines in the system. By noting with $1-A(\delta)$ the probability that a machine would operate without the performer's intervention in a time interval $\delta$, it is accepted that the need of a performer's intervention to the machines is independent, the probability that no machine from the $N-n$ ones operating would not require the performer's intervention shall be:

$$
[1-A(\delta)]^{N-n}
$$

The probability that at least one of the $N-n$ (machines that are operating) would need the performer's intervention shall be given by:

$$
1-[1-A(\delta)]^{N-n}=(N-n) \lambda \delta+O(\delta)
$$

where: $O(\delta)$ - has the property that: $\lim _{\delta \rightarrow \infty} \frac{O(\delta)}{\delta}=0$

The probability to complete a performer's intervention (meaning to restart the operation of the machine served) in a time interval is given by the relation:

$$
B(\delta)=\mu \delta+0(\delta)
$$

The situations that at the moment $t+\delta$ there would be $n$ machines in the waiting system are the following: at the moment $\mathrm{t}$ there are $\mathrm{n}$ machines in the system and in the time interval $\mathrm{t}$ at $t+\delta$ there are no machines to be served or machines the serving of which has been completed; at the moment $t$ there are $n-1$ machines in the waiting system and in the time interval from $\mathrm{t}$ to $t+\delta$ it is required to serve a machine and no machine has been commissioned within this interval; at the moment $\mathrm{t}$ there are $t+\delta$ machines in the waiting system and in the time interval from t to $t+\delta$ it is not required to additionally serve another machine, but serving a machine that is commissioned without supervision is determined; within the time 
interval $\mathrm{t}$ at $t+\delta$, a variation of the number of machines greater than one is recorded in the waiting system, whatever the number of machines may be in the waiting system.

The performer's inactivity average shall be:

$$
T_{e}^{a}=\sum_{a=0}^{1}(1-n) p_{n}=p_{0}
$$

The average number of machines operating:

$$
M\left(N-\bar{N}_{g}\right)=\frac{1}{\rho}\left(1-p_{0}\right)
$$

The probability that a machine would be waiting to be served, which is the performer's occupational probability, is:

$$
p(>0)=\sum_{n=1}^{N} p_{n}=1-p_{0}
$$

In order to determine the average waiting time of the machines in the case of a permanent operating regime, the average of machines halts is no longer $\lambda$, but $\lambda\left(N-\overline{N_{g}}\right)$. It results from here:

$$
\bar{N}_{f}=\lambda\left(N-\bar{N}_{g}\right)
$$

and the average waiting time of the machine to be served from the relation:

$$
T_{f}=\frac{1}{\left(N-\bar{N}_{g}\right)}\left[N-\frac{1+\rho}{\rho}\left(1-p_{0}\right)\right]
$$

The average waiting time in the system shall be:

$$
T_{s}=T_{f}+\frac{1}{\mu}\left[\frac{N}{1-p_{0}}-\frac{1+\rho}{\rho}\right] .
$$

The optimal number of machines operating in random regime, served by a performer is determined based on an economic function.

\section{The result of using the models}

A performer's serving pattern of several machines at random time intervals requires going through the following stages: choosing the serving area that is to be 
studied; performing observations on the number of servings on the time unit chosen; applying the test in order to verify whether the phenomenon is of Poisson type; choosing the variable depending on the one that is to optimise the serving of several machines (the Area); optimisation itself of the process of a performer serving several machines, by minimising the function in relation to the number of machines served and calculation of additional indicators of the optimal variable.

In a production unit consisting in identical machines, making products and homogeneous operations, a problem rises for determining the optimal number of machines served by a performer. From the statistical measures (Tab. 1) it was discovered that the number of servings differs from one time interval to another, being of random feature. It was also discovered that the serving time of a machine is $t e=1.5$ minutes/machine served.

Table 1

Frequency of the serving categories

\begin{tabular}{|l|c|c|c|c|c|c|}
\hline Categories of servings noticed $\left(n_{i}\right)$ & 3 & 4 & 5 & 6 & 7 & 8 \\
\hline Frequency of categories of servings $f\left(n_{i}\right)$ & 8 & 23 & 24 & 21 & 14 & 6 \\
\hline
\end{tabular}

The following data are also given: $W_{h}=250$ lei/hour - productivity of a worker's work per hour; $P_{h}=400$ lei/hour - productivity of production achieved by a machine during one hour of operation. Solving this problem requires going through the following stages:

Stage 1. For the study, the area of machines that are to be multi-served is chosen.

Stage 2. Observations are performed on the number of hourly servings per machine in the area of machines.

The experimental data of a machine operation performed in 96 intervals of one hour each are given in Table 1. It results from Table 1 that the number of servings differs from one interval to another, having a random feature. In order to simplify the analysis, it was ordered by categories and namely: 3 servings/hour were noticed 8 times; 4 servings/hour 23 times; .. 8 servings per hour 6 times. By using the data in Table 1, the average number of machines servings per hour is calculated; the calculation is done by means of table 2 .

Table 2

Calculation of the average number of servings per hour

\begin{tabular}{|l|c|c|c|c|c|c|c|}
\hline Categories of serving $\left(n_{i}\right)$ & 3 & 4 & 5 & 6 & 7 & 8 & $\begin{array}{l}\text { Total categories of } \\
\text { serving }=6\end{array}$ \\
\hline $\begin{array}{l}\text { Frequency of servings } \\
\text { in a category } f\left(n_{i}\right)\end{array}$ & 8 & 23 & 24 & 21 & 14 & 6 & $\sum f_{\left(n_{i}\right)}=N=96$ \\
\hline $\begin{array}{l}\text { Number of units served } \\
\text { on a category }\left(n_{i} \cdot f\left(n_{i}\right)\right)\end{array}$ & 24 & 92 & 120 & 126 & 98 & 48 & $\sum n_{i} \times f_{\left(n_{i}\right)}=508$ \\
\hline
\end{tabular}


The average number of machines served $(\lambda)$ in one hour is

$$
\lambda=\frac{\sum n_{i} \times f_{(n i)}}{N}=\frac{508}{96}=5.29166 .
$$

Stage 3. The assumption on the Poisson distribution of the occurrence of machine serving is verified with the $X^{2}$ test.

The Poisson theoretical probabilities (determined by calculation or from the tables of the Poisson function) for 6 categories of serving are given in Table 3.

Table 3

The Poisson theoretical probabilities for $\lambda=\mathbf{5 . 2 9 1 6 6}$

\begin{tabular}{|c|c|}
\hline Category of servings (ni) & $\mathrm{P}(n)$ \\
\hline 3 & $\mathrm{P}(3)=0.1241$ \\
\hline 4 & $\mathrm{P}(4)=0.1642$ \\
\hline 5 & $\mathrm{P}(5)=0.1737$ \\
\hline 6 & $\mathrm{P}(6)=0.1532$ \\
\hline 7 & $\mathrm{P}(7)=0.1158$ \\
\hline 8 & $\mathrm{P}(8)=0.1076$ \\
\hline
\end{tabular}

The assumption on the Poisson distribution of the occurrence of machine serving is verified with the $X^{2}$ test, by means of Table 4 .

The number of freedom degrees $\left(N_{g l}\right)$ is determined by the relation

$$
N_{g 1}=n_{i}-2 \text {. }
$$

In the example we looked at $n_{i}=6(3,4,5,5,7,8)$; therefore

$$
N_{g i}=6-2=4 \text { freedom degrees. }
$$

Table 4

Calculation of $X_{0}^{2} N=96$

\begin{tabular}{|c|c|c|c|c|c|}
\hline $\mathrm{n}_{\mathrm{i}}$ & $f_{(n i)}$ & $P_{(n)}$ & $N_{i}=N \times P_{n}$ & $f_{\left(n_{i}\right)}-N_{i}$ & $\frac{\left(f_{\left(n_{i}\right)}-N_{i}\right)^{2}}{N_{i}}$ \\
\hline 3 & 8 & 0.1241 & 11.9146 & -3.9136 & 0.1595 \\
\hline 4 & 23 & 0.1642 & 15.7632 & 7.2368 & 0.5455 \\
\hline 5 & 24 & 0.1737 & 16.6752 & 7.3248 & 0.5588 \\
\hline 6 & 21 & 0.1532 & 14.7072 & 6.2928 & 0.4125 \\
\hline 7 & 14 & 0.1155 & 11.1168 & 2.8832 & 0.0866 \\
\hline 8 & 6 & 0.0766 & 7.3536 & -1.3536 & 0.0191 \\
\hline \multicolumn{7}{|c|}{$X_{0}^{2}=\sum \frac{\left(f_{(n i)}-N_{t}\right)^{2}}{N_{i}}$} \\
\hline
\end{tabular}


The assertion $\varepsilon=0.05$ is also chosen for $N_{g 1}=4$ freedom degrees, the value $X^{2}=9.49$ is found in the tables for the distribution $X^{2}$.

Because: $X^{2}>X_{0}^{2},(9.49>1.782)$ it may be accepted the assumption of distributing the machine for serving is based on Poisson's law with $\lambda=5.29166$ servings per hour.

Stage 4. Serving is optimised based on that variable which is the number of machines served, which shall be determined in various variants, the function to optimise being $f_{\left(m_{i}\right)}=W_{i} \times T_{e}^{a}+P_{a} \times \bar{N}_{f} \times \bar{T}_{f} \rightarrow$ minimum!

Stage 5. The indicators of random serving of several machines are calculated by a performer in many serving variants and by minimising the function $f_{\left(m_{i}\right)}$, the optimal serving variant is chosen.

Variant $m_{i}=3$

If $N=m_{i}$ is the number of machines served, then:

$$
\lambda_{3}=m_{i} \times \lambda=3 \times 5.29=15.87 \text { machines are to be averagely served per hour. }
$$

The serving time of a machine is $t e=1.5$ minutes on a serving of one machine, within an interval of 60 minutes. The performer may averagely do:

$$
\mu=\frac{60}{t e}=\frac{60}{1.5}=40 \text { servings per hour. }
$$

The serving factor or performer's occupational degree shall be:

$$
\rho_{3}=\frac{\lambda_{3}}{\mu}=\frac{15.87}{40}=0.397 \text {. }
$$

The probability that all 3 machines would operate at a given moment or the probability of not waiting is achieved from the relation:

$$
\begin{gathered}
P_{0}=\frac{1}{1+\sum_{n=1}^{m_{i}} \frac{m i !}{\left(m_{i}-n\right) !} \rho^{n}}, \\
P_{03}=\frac{1}{3,512} \approx 0.285
\end{gathered}
$$

The average number of machines at standstill in the system at a given moment:

$$
\bar{N}_{g}=m i-\frac{1}{\rho}\left(1-P_{0}\right) \approx 1.199 \text { machines. }
$$

The average number of machines waiting to be served results from:

$$
\bar{N}_{f}=\bar{N}_{g}-\left(1-P_{0}\right)=0.484 \text { machines }
$$


The average waiting time of a machine in the string during one hour shall be:

$$
\bar{T}_{f}=\frac{\bar{N}_{f}}{\left(m i-\bar{N}_{g}\right)}=0.0169 \text { hours/hour. }
$$

The average waiting time in the system results from:

$$
\bar{T}_{s}=\frac{\bar{N}_{g}}{\mu \rho\left(m i-\bar{N}_{g}\right)}=0,0419 \text { hours/hour. }
$$

The performer's average waiting time in one hour is calculated thus:

$$
T_{e}^{a}=P_{(0)}=0.285 \text { hours } / \text { hour } .
$$

The economic function for the variant $m_{i}=3$ machines is calculated thus:

$$
\begin{gathered}
f_{(m 3)}=\bar{W}_{h} \times \bar{T}_{e}^{a}+\bar{P}_{h} \times \bar{N}_{f} \times \bar{T}_{f 3} \\
f_{(m 3)}=74.52 \text { lei/hour }
\end{gathered}
$$

\section{Conclusions}

The values of the serving variants have been analogically calculated for $m_{i}(i=4,5,6)$, and are summarised in Table 5 .

Table 5

Table of serving and decisional variants

\begin{tabular}{|c|c|c|c|c|}
\hline \multirow{2}{*}{ Indicators } & \multicolumn{4}{|c|}{ Serving variants for $m_{i}$} \\
\hline & 3 & 4 & 5 & 6 \\
\hline$\lambda_{i}$ & 15.87 & 21.16 & 26.45 & 31.74 \\
\hline$\mu_{i}$ & 40 & 40 & 40 & 40 \\
\hline$\rho_{i}$ & 0.357 & 0.529 & 0.6613 & 0.7935 \\
\hline$p_{(0) i}$ & 0.285 & 0.08398 & 0.0146 & 0.0015 \\
\hline $\bar{N}_{e i}$ & 1.1990 & 2.2684 & 3.5099 & 4.7417 \\
\hline $\bar{N}_{f i}$ & 0.484 & 1.3524 & 2.5245 & 3.793 \\
\hline $\bar{T}_{f i}$ & 0.0169 & 0.0369 & 0.0641 & 0.0937 \\
\hline $\bar{T}_{e i}$ & 0.0419 & 0.0619 & 0.089 & 0.1187 \\
\hline $\bar{T}_{e}^{a}$ & 0.285 & 0.08393 & 0.0146 & 0.0015 \\
\hline$f_{(m i)}$ & 74.52 & 40.94 & 68.38 & 140.66 \\
\hline \multicolumn{5}{|c|}{ The optimal decision is $m_{i}=4$} \\
\hline
\end{tabular}


The calculations were not performed anymore for serving 7 and 8 machines, because the function $f_{\left(m_{i}\right)}$ to minimise from $m_{i}=6$ represents a sharp increase.

It results from table 5 that the optimal serving is for $m_{i}=4$ machines.

\section{References}

[1] Askin R., Standridge C., Modeling and analysis of manufacturing systems, John Wiley \& Sons, Inc., New York, NY 1993.

[2] Chase R.B., Aquilano N.J., Jacobs F.R., Operations management for competitive advantage (10th ed.), McGraw-Hill, Boston, MA 2004.

[3] Dima I.C., Using multiservice of industrial management, WWZPCz, Czestochowa 2010.

[4] Dima I.C., Marcincin I.N., Grabara J., Pachura P., Kot S., Man M., Operational management systems of the production achieved in flexible manufacturing cells, Technical University of Kosice, Presov 2011.

[5] Dima I.C., Grabara I., Pachura P., Kot S., Modrak V., Marcincin I.N., Man M., Multiserving operational management system of the production achieved in flexible manufacturing cells, WWZPCz, Czestochowa 2011.

[6] Gen M., Cheng R., Genetic algorithms and engineering design, Wiley, New York 1997.

[7] Goldberg D.E., Genetic algorithms in search, optimization, and machine learning, AddisonWesley Reading, MA 1989.

[8] Lee Y.D., Lee T.E., Stochastic cyclic flow lines with blocking: Markovian models. OR-Spektrum 2005, 27(4), 551-568.

[9] Li S.Z., Markov random field modeling in computer vision, Springer-Verlag 1995.

[10] Modrak V., Pandian R.S., Operations Management Research and Cellular Manufacturing Systems, IGI Global, Hersey 2011.

[11] Santana R., A Markov network based factorized distribution algorithm for optimization, Proceeding of the 14th European Conference on Machine Learning, Berlin 2003.

[12] Slack N., Chambers S., Johnston R., Operations management, Financial Times/Prentice Hall, Harlow, MA 2001.

[13] Ślusarczyk B., Industrial Policy Development Towards Sustainability, [in:] The Role of Business in Achieving Sustainability. Part 2: Implication for Industry, Modrak V., Ślusarczyk B. (eds.), Technical University Kosice, Presov 2010. 